\title{
DINÂMICAS E DILEMAS DA AGRICULTURA EMPRESARIAL NA FRONTEIRA AGRÍCOLA PIAUIENSE
}

\section{Resumo}

Antônio Joaquim da Silva ${ }^{1}$

Este artigo pretende analisar o contexto de reorganização do espaço em Uruçuí, a fim de revelar dinâmicas, estratégias e interesses de reprodução da agricultura empresarial no cerrado piauiense. Uruçuí destaca-se por ser pioneiro em abrigar empresas de agronegócios no Piauí, o que possibilita entender a intensidade das transformações socioespaciais ocasionadas pela agricultura empresarial. A metodologia do estudo se embasou nas pesquisas bibliográfica, documental e levantamento, sendo esta alicerçada por meio de entrevistas semiestruturadas com três empreendimentos graníferos do município. Concluiu-se que a difusão da agricultura empresarial em Uruçuí organizava-se em redes técnicas caracterizadas pelo uso intensivo de capital, tecnologia e informação, marcadas por ações de políticas públicas federal e estadual, cujas benesses contribuíram para a constituição de um rentável mercado de terras orientado pelo preço da soja nos mercados doméstico e global, o que acentuou a concentração fundiária e a subordinação dos trabalhadores da agricultura familiar tradicional.

Palavras-chave: baixo preço da terra; cerrado piauiense; modernização agrícola; soja.

\section{DYNAMICS AND DILEMMAS OF BUSINESS AGRICULTURE IN THE AGRICULTURAL FRONTIER OF PIAUÍ STATE, BRAZIL}

\begin{abstract}
This article intends to analyze the reorganizational context of the space in Uruçuí, in order to reveal dynamics, strategies and interests of business agriculture reproduction in the Cerrado of Piauí. Uruçuí stands out as the first to house agribusiness companies in the State of Piauí, which makes it possible to understand the intensity of socio-spatial transformations caused by the agriculture business. The methodology of the study was based on the bibliographical, documentary researches and data collection, which was supported by semi-structured interviews with three grain enterprises of Uruçuí city. It was concluded that the diffusion of the agriculture business in Uruçuí was organized in technical networks characterized by the intensive use of capital, technology and information, and characterized by the actions of federal and state public policies, whose benefits contributed to the creation of a profitable land market driven by the price of soybeans in the domestic and global markets, which accentuated a land concentration and the subordination of the traditional family farming workers.
\end{abstract}

Keywords: low price of land; cerrado of Piauí; agricultural modernization; soy.

\footnotetext{
1 Doutor em Desenvolvimento e Meio Ambiente pela Universidade Federal do Piauí (UFPI/PRODEMA Associação em Rede). Pela mesma instituição, concluiu em 2008, o curso de Licenciatura Plena em Geografia. Atualmente é professor (DE) no Instituto Federal de Educação, Ciência e Tecnologia do Piauí (IFPI/Campus Teresina Central).

E-mail: antoniojoaquim@ifpi.edu.br
} 


\section{DINÁMICAS Y DILEMAS DE LA AGRICULTURA EMPRESARIAL EN LA FRONTEIRA AGRÍCOLA PIAUIENSE, BRASIL}

\section{Resumen}

Este artículo intenta analizar el contexto de reorganización del espacio en Uruçuí, a fin de revelar dinámicas, estrategias e intereses de reproducción de la agricultura empresarial en el cerrado piauiense. Uruçuí se destaca por ser el primer en albergar empresas de agronegocios en Piauí, lo que posibilita entender la intensidad de las transformaciones socioespaciales ocasionadas por la agricultura empresarial. La metodología del estudio se basó en las investigaciones bibliográfica, documental y levantamiento, siendo esta fundamentada por medio de entrevistas semiestructuradas con tres emprendimientos graníferos del municipio. Se concluyó que la difusión de la agricultura empresarial en Uruçuí se organizaba en redes técnicas caracterizadas por el uso intensivo de capital, tecnología e información, y marcadas por las acciones de políticas públicas federal y estadual, cuyas beneses contribuyeron a la constitución de un marco el mercado de tierras orientado por el precio de la soja en los mercados doméstico y global, lo que acentuó la concentración agraria y la subordinación de los trabajadores de la agricultura familiar tradicional.

Palabras clave: bajo precio de la tierra; cerrado piauiense; modernización agrícola; soja.

\section{INTRODUÇÃO}

O processo de difusão de um novo modus operandi na agricultura dos cerrados brasileiros, iniciado nos anos 1970, tem configurado uma nova geografia de espaços agrários (ELIAS, 2012), o que tem aprofundado e acirrado a divisão territorial do trabalho, repercutindo na reformulação da distribuição de funções produtivas do território (HAESBAERT, 2005).

Como exemplo axiomático dessa reestruturação produtiva, destaca-se o município de Uruçuí, por ser pioneiro em abrigar a agricultura empresarial no Piauí, onde a migração de produtores e investidores econômicos, interessados em produzir grãos, sobretudo soja, oriundos de diversas regiões do país, marcadamente detentores de know-how e conectados às redes/fluxos da economia globalizada, tem alterado o sentido da produção agrícola, passando a interferir na posse e no uso da terra, o que tem transformado a paisagem, o trabalho e os modos de vida rurais (ALVES, 2003).

Notadamente, Silva, Monteiro e Barbosa (2017) evidenciam que o fenômeno de abertura e expansão da fronteira agrícola no Piauí, comandado pelo agronegócio e incentivado pelas políticas públicas, tem intensificado o uso de capital, tecnologias modernas e inovações de gestão, condicionando a reorganização do espaço por meio de formas mais avançadas de produção, circulação e consumo. 
Por outro lado, para Martins (2014), esse movimento progressivo de deslocamento da fronteira agrícola manifesta um dos modos pelos quais ocorre a reprodução ampliada do capital, o da sua expansão territorial.

Essa expansão territorial, segundo Bernardes (2009), traz implícita uma nova ordem social e econômica marcada pela apropriação e domínio dos recursos naturais, pelo incremento de redes técnicas e pela ampliação da diferenciação socioespacial. A autora critica a participação institucional no contexto de avanço da fronteira agrícola, principalmente a finalidade da modernização e do desenvolvimento.

Diante do exposto, apresentam-se alguns questionamentos para a reflexão sobre a complexidade dos "efeitos territoriais" " (SAQUET, 2015) causados pela consolidação da agricultura empresarial em Uruçuí, como: Quais as lógicas e expressões da consolidação da agricultura empresarial em Uruçuí, mormente as que envolvem a terra, o trabalho, a produção, o mercado e as benesses governamentais? E como se manifesta a interferência da soja (carrochefe da expansão do agronegócio nos cerrados brasileiros) no contexto de ocupação empresarial em Uruçuí?

Registra-se que agronegócio deriva de agribusiness, expressão surgida nos Estados Unidos da América nos anos 1950 para designar a interdependência encontrada nos negócios dos três setores econômicos. Entretanto, neste artigo, entende-se o agronegócio segundo a análise de Silva (2016), vendo-o como um projeto político/ideológico orquestrado por um pequeno grupo de capitalistas agrários que defendem a participação do Estado na concessão de benesses de um segmento social que produz para o mercado de commodities, por sua vez, articulado aos imperativos do mercado financeiro mundial.

Assim, pretende-se analisar o processo de reorganização do espaço em Uruçuí, a fím de revelar dinâmicas, estratégias e interesses de reprodução da agricultura empresarial no cerrado piauiense. Para tanto, o artigo está dividido em cinco seções, além desta introdução. A próxima seção versa sobre a metodologia da pesquisa. A terceira seção trata de aspectos gerais (particularmente, políticos e sociais) da ocupação empresarial do cerrado piauiense, como em Uruçuí. A quarta seção socializa os resultados da investigação empírica. E a quinta seção apresenta as considerações finais do estudo.

2 A expressão efeitos territoriais foi formulada por Robert Sack para analisar as complexas teias de relações entre Estado e agentes do capital, intensificadas com a mobilidade geográfica do capital, do trabalho e da comunicação, e com o incremento de relações impessoais para o controle do território (SAQUET, 2015). 


\section{METODOLOGIA}

Este artigo qualiquantitativo apresenta parte dos resultados de uma pesquisa de doutoramento realizada no cerrado piauiense, em 2015 e 2016. Por isso, tem caráter descritivo/explicativo, por descrever, interpretar e avaliar a complexidade de uma realidade, fatos, fenômenos e processos (SANTOS, 2012).

Os procedimentos técnicos se fundamentaram nas pesquisas bibliográfica, documental e levantamento, sendo esta subsidiada por meio de entrevistas semiestruturadas (orientadas por tópicos-guia), aplicadas em três empreendimentos graníferos (Figura 1), selecionados intencionalmente por apresentarem dimensões acima de 15 módulos fiscais (em Uruçuí, um módulo fiscal corresponde a 75 hectares), produzirem em larga escala orientados por inovações tecnológicas, manterem estreitas relações com os mercados doméstico e global e por estarem acessíveis para compor a amostra. Tais características dos empreendimentos graníferos qualificam-os como reais representantes do agronegócio (AGUIAR, MONTEIRO, 2005).

Figura 1: Localização espacial de Uruçuí/PI e empreendimentos graníferos 


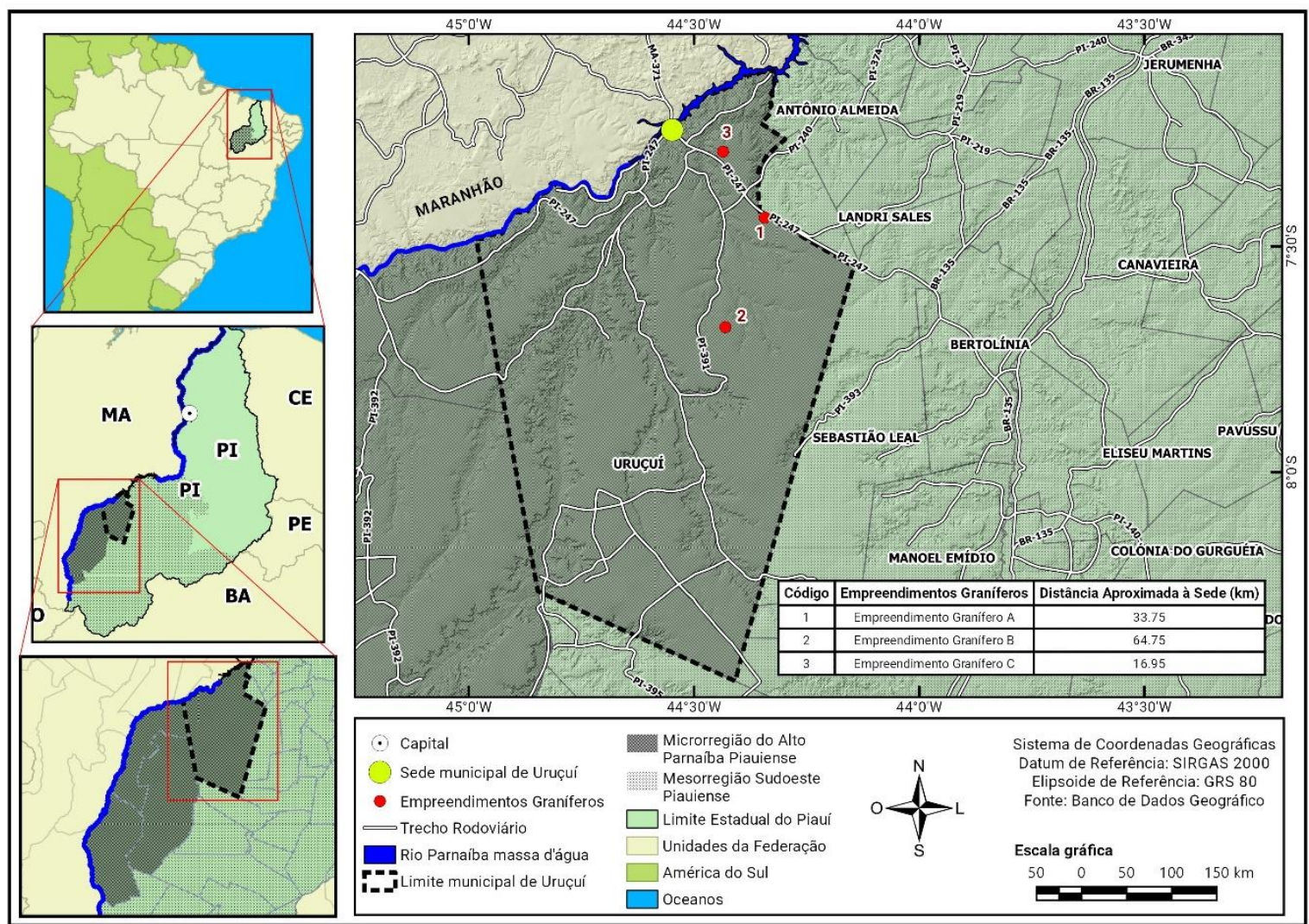

Fonte: Adaptado de Silva, Monteiro e Barbosa (2017)

A partir da Figura 1, destaca-se que Uruçuí localiza-se na microrregião geográfica Alto Parnaíba Piauiense, possui área territorial de $8.452,025 \mathrm{~km}^{2}$ e limita-se, ao Norte, com o estado do Maranhão e o município piauiense de Antônio Almeida, ao Leste, Landri Sales, Sebastião Leal e Manoel Emídio, ao Sul, Alvorado do Gurgueia e Palmeira do Piauí e, a Oeste, Baixa Grande do Ribeiro, Ribeiro Gonçalves e o estado do Maranhão. E que os empreendimentos pesquisados ocupavam extensas áreas de chapadas.

Considerou-se ainda, para a investigação, o tempo de instalação dos empreendimentos em Uruçuí, preferencialmente, em distintos períodos, para identificar semelhanças e diferenças na configuração da agricultura empresarial, sobretudo questões que envolviam terra, trabalho, produção, infraestrutura e mercado. Dessa forma, elegeram-se os empreendimentos A, B e C, inaugurados em 2012, 1995 e 1997, respectivamente (Figura 1).

Os dados foram tabulados mediante o uso do programa eletrônico Statistical Package for the Social Science. A análise qualitativa dos discursos gravados sustentou-se na transcrição (MANZINI, 2006) e leitura das falas, isto é, das experiências e relatos de histórias de vida 
(QUEIROZ, 1983), respeitando os depoimentos dos graníferos ${ }^{3}$, pois para Orlandi (2000, p.61), essa técnica possibilita a "compreensão de como um objeto simbólico produz sentidos, como ele está investido de significados para e por sujeitos". Além do mais, a investigação foi aprovada pelo Comitê de Ética em Pesquisa da Universidade Federal do Piaú, por meio do Parecer Consubstanciado de Aprovação Ética, sob o número 1087335, o que garantiu o anonimato das identidades dos sujeitos. Salienta-se ainda, que os depoimentos dos graníferos foram referenciados por meio de uma sequência numérica.

\section{A OCUPAÇÃO EMPRESARIAL DO CERRADO URUÇUIENSE}

A partir dos anos 1970 instaura-se o movimento de reprodução ampliada do capital no cerrado piauiense, conformado na chamada frente pioneira que, segundo Martins (2014, p. 135), traz "implicitamente a ideia de que na fronteira se cria o novo, nova sociabilidade, fundada no mercado, na contratualidade das relações sociais", sendo, portanto, "mas do que o deslocamento da população sobre territórios novos, mas do que supunham os que empregam essa concepção no Brasil”.

Sem embargo, a ocupação empresarial do cerrado piauiense tem nas políticas governamentais as condições gerais para o desembarque de migrantes oriundos de diversas regiões do país, sobretudo, gaúchos e paranaenses, denominados genericamente de sulistas, e marcadamente originários da agricultura familiar (ALVES, 2004; HAESBAERT, 2005). No novo território, os sulistas irão promover mudanças espaciais e sociais sustentadas na modernização tecnológica, em novas concepções de vida e relações com o mercado.

Monteiro e Aguiar (2006) ressaltam que não obstante a inserção da ocupação e uso do cerrado piauiense ter iniciado na década de 1970, através de subsídios do Fundo de Investimentos do Nordeste (FINOR-Agropecuário) e do Fundo de Investimento Setorial (FISET), somente a partir da década de 1990, ocorreu a intensificação da instalação de grandes empreendimentos produtores de grãos, em particular, soja, atraídos, sobretudo, pelo baixo preço da terra, pelo esgotamento de solos agricultáveis em outras regiões do país (principalmente o Centro-Oeste), pela proximidade dos mercados consumidores, pelas condições favoráveis de clima, solo e topografia e pelos recursos facilitados dos governos federal e estadual.

3 Neste artigo, utiliza-se a expressão graníferos para designar os produtores da agricultura empresarial. Segundo Silva (2016), especificamente nos cerrados do Piauí, os graníferos ou agroempresários são médios e grandes proprietários de terras, originários de outras regiões do país, cuja produção agrícola mantêm uma estreita ligação entre técnica, ciência, informação e negócios. 
Com relação às características naturais do cerrado, Santos e Araújo (2007, p.84) destacam como aspectos importantes à ocupação empresarial:

[...] chuvas regulares na maior parte da estação chuvosa; pluviosidade situando-se em torno de $1.100 \mathrm{~mm} / \mathrm{ano}$, sendo que $65 \%$ das precipitações ocorrem nos meses de dezembro e março; topografia semiplana, favorecendo o uso da mecanização na agricultura intensiva; existência de jazidas de calcário dolomítico, próprio para a correção de solos na própria região dos cerrados; elevado grau de luminosidade durante todo o ano $[\ldots]$.

Concomitante a esses aspetos físicos, os referidos autores citam também a ampliação da rede de energia elétrica rural, que viabilizou a implantação de projetos agroindustriais, e as pesquisas científicas desenvolvidas pela Embrapa/Meio Norte sediada em Teresina/PI, que adaptou variedades de soja às condições ambientais do cerrado piauiense.

Especificamente sobre as políticas governamentais, sublinha-se que o FINORAgropecuário foi viabilizado pela Superintendência de Desenvolvimento do Nordeste (SUDENE) e consistiu em um "mecanismo facilitador para a aquisição de terras, por parte de empresários do Centro-Sul e do Nordeste", enquanto o FISET concedeu "incentivos físcais com o objetivo de proporcionar o desenvolvimento setorial, no caso do Piauí, para o reflorestamento" (ARAÚJO, ARAÚJO, 2007, p.47).

Notadamente, o governo do Estado do Piauí, por meio da Companhia do Desenvolvimento do Piaú (COMDEPI), promoveu o repasse de grandes extensões de terras públicas às empresas interessadas em adquirir áreas para execução de "pretensos" projetos agropecuários e de reflorestamento, sobretudo, caju, o que favoreceu a concentração da estrutura fundiária, a grilagem e a especulação valorativa de terras (PEIXINHO, SCOPEL, 2009).

Nessa perspectiva, concorda-se com a análise de Martins (2014, p.137), de que a expansão da fronteira, em particular, nos cerrados, revela uma das faces da reprodução ampliada do capital, na medida em que:

[...] a sua reprodução extensiva e territorial, essencialmente mediante a conversão de terra em mercadoria e, portanto, em renda capitalizada, como indicava e indica a proliferação de companhias de terras e negócios imobiliários nas áreas de fronteira em que a expansão assume essa forma [...].

Por conseguinte, o contexto de ocupação do cerrado piauiense repercutiu em uma intensa dinâmica produtiva que redefiniu a economia agrícola (ELIAS, 2006a), com a instalação 
de comércios e serviços especializados voltados à agricultura empresarial (sementes, maquinários, defensivos, adubos, etc.). Também ganharam relevância outros ramos da economia destinados ao atendimento do consumo da população, principalmente citadina (agências bancárias, hotéis, supermercados, serviços educacionais e diversos tipos de lojas, como de vestuário, de eletrodomésticos, da construção civil, etc.), cuja implantação exigiu transformações no espaço urbano (FAÇANHA, LEAL, 2009).

Todavia, Silva, Monteiro e Barbosa (2015) evidenciam que o cerrado piauiense antes da chegada da agricultura empresarial possuía baixa densidade demográfica, poucos núcleos urbanos, isolamento das comunidades, sobretudo nos fundos de vales, e presença de grandes propriedades criadoras de gado. Ou seja, o cerrado piauiense configurava um espaço onde predomina a concentração privada de grandes extensões de terras e uma economia amonetária calcada no trabalho puro e simples de personagens figurativos da história imemorial do Piauí, como vaqueiros, caboclos, índios, escravos, camponeses, posseiros e agregados.

Como consequência da inserção da agricultura piauiense à economia globalizada e, no caso específico, o município de Uruçuí, o espaço rural tem sofrido intensas alterações. As áreas de platôs ou chapadas, chamados popularmente de terras dos Gerais, localizados ao redor dos vales, foram estrategicamente ocupadas pela agricultura empresarial, por apresentarem um baixo preço da terra e topografia plana favorável à utilização de maquinário e implementos agrícolas (ALVES, 2009; PEIXINHO, SCOPEL, 2009).

As terras dos Gerais simbolizavam um lugar de vital importância para as populações originárias do cerrado, como camponeses, indígenas e quilombolas, por exemplo, devido serem utilizadas para a caça de animais silvestres e para a criação de gado, como também para a retirada de lenha, madeira, frutas nativas, plantas medicinais, mel, etc. (ALVES, 2009; PEIXINHO, SCOPEL, 2009).

Com a introdução da agricultura empresarial em Uruçuí, o sudoeste do Piauí conformouse como área mais dinâmica para a produção granífera, sobretudo, soja. Entre 1990 e 2014, a área plantada com soja na região aumentou 398 vezes, expandindo de 1.560 para 620.895 hectares (SILVA, MONTEIRO, BARBOSA, 2015). Além disso, quanto à quantidade produzida, o sudoeste piauiense registrou, em 2015, o total de 1.752 .659 toneladas de soja, o que representou 98,86\% da produção estadual fixada em 1.772 .722 toneladas (IBGE, 2017).

Diante do exposto, corrobora-se com Pacheco (2017), de que tal ocupação empresarial, por um lado, representou importantes avanços econômicos, na medida em que tornou viável a 
produtividade da terra, o que possibilitou atender os mercados doméstico e global. Por outro lado, repercutiu em impactos sociais e ambientais. No social, por exemplo, passou a interferir na posse da terra e nos modos de vida da população rural. E, no ambiental, agravou o problema dos desmatamentos, além do incremento de agrotóxicos para controle de pragas, ervas daninhas, fungos e outras ameaças.

\title{
A SOJA NA DINÂMICA DO MERCADO DE TERRAS EM URUÇUí E AS REPERCUSSÕES NA QUESTÃO FUNDIÁRIA
}

Evidenciou-se, em conformidade com a pesquisa empírica, que especificamente em Uruçuí o baixo preço da terra foi condição sine qua non para a introdução da agricultura empresarial, como pode ser observado em uma narrativa de memória de um granífero natural do estado do Paraná:

\begin{abstract}
Minha cidade natal é Pato Branco, Paraná, toda minha família é de agricultores, de agricultura familiar. Na realidade eu desenvolvi a agricultura durante 17 anos, em Mato Grosso do Sul, eu produzia em São Gabriel do Oeste (MS), de onde eu vim. Eu não tinha terra lá, eu era arrendatário, eu não consegui comprar terra lá, e o preço da área, que é o preço que eu pagava de aluguel, na verdade não é aluguel, na agricultura se fala arrendamento, o valor da saca de soja que eu pagava por um ano, por um hectare lá, de arrendamento, eu comprei aqui. Então, a primeira opção, em função do valor da terra ser mais barato (Entrevistado número 1).
\end{abstract}

A partir desse fragmento de história de vida, percebeu-se que os migrantes que desembarcaram no cerrado piauiense eram originários da agricultura familiar. De fato, no movimento de expansão da fronteira, o sulista (granífero) preservava um modo de vida sui generis - "o da família que trabalha na agricultura, para si mesma, que não trabalha para os outros" (MARTINS, 2014, p.109).

Entendeu-se, também, que a chegada em Uruçuí, possibilitou ao granífero a substituição da condição de rendeiro (como também de pequeno proprietário), em terras de ocupação antiga. Adenda-se, de acordo com Kautsky (1986), que o arrendamento consiste em um sistema de uso do solo no qual o agricultor paga um tributo ao proprietário/capitalista, pela disponibilização do cultivo da lavoura.

Em virtude disso, verificou-se que a realidade encontrada em Uruçuí se harmonizou com a análise de Alves (2006, p.243), de que os migrantes se instalaram no cerrado com capital suficiente para adquirirem "grandes extensões de terras, transformando uma parte delas em unidade produtiva de grãos de médio e grande porte, principalmente soja, e deixando a outra parte como reserva de valor". 
Alves (2006) acrescenta também que os graníferos em sua trajetória de vida por outra fronteira agrícola foram acumulando riquezas, tornando-se inclusive grandes empresários do capital agrícola. Mas, na sua origem, muitos deles eram originários da agricultura camponesa com pouca ou nenhuma terra.

Esse cenário se alinha à opinião de Velho (1972) de que nas áreas de expansão da fronteira agrícola, o pioneiro busca não apenas aumentar o povoamento espacialmente, mas intensificá-lo, criando novos e mais elevados padrões de vida, além do incremento de melhoramentos no campo da técnica.

Além disso, constatou-se que a totalidade dos graníferos reconhecia a soja como moeda corrente para a comercialização de terras e para a aquisição de tecnologias, insumos e sementes, como expressou um entrevistado.

\begin{abstract}
A gente costuma dizer que a soja, por si só, é um cheque-visado [risos], e eu posso tá hoje, exatamente como a gente tá conversando hoje, né, dia 3 de julho de 2015, eu posso erguer o telefone agora e vender a soja que eu ainda nem plantei, ligar para uma trading e travar negócio pra safra futura. Então, ela [soja] tem uma liquidez baseada pela bolsa de Chicago, uma liquidez rápida; milho não é assim, arroz não é assim, são vários produtos que a gente tem uma dificuldade, e soja, você quando tem, você vende, pode variar o preço em função de coisas específicas, como seca nos Estados Unidos, seca no Brasil, a conjuntura internacional, mas de um modo geral, a soja é dinheiro a hora que você quer. Então, nós temos uma moeda entre os agricultores que baliza [orienta] as compras de terras, isso vale no Paraná, vale no Centro-Oeste, e não é diferente aqui [Uruçuí]. A gente baliza um preço de terra em função de uma saca de soja, por exemplo. Então, eu vou te falar quanto eu paguei em reais à época, é ruim até porque eu tenho que saber o dólar da época também, e como a soja, ela se atualiza conforme o mercado, conforme o dólar, então, a base da compra da área aqui foi em torno de duas sacas de soja, que se for transformar em reais, hoje, daria em torno de R\$ 120,00. Então, é uma moeda que por si só, ela se atualiza. Então, na época, foi paga em torno de duas sacas de soja por hectare, que no dia de hoje dá $\mathrm{R} \$ 120,00$. Logicamente, essa é a conta pura e simples, depois você tem a documentação, você tem a terra nua [desmatada], aí você tem mais toda a parte burocrática de compra, né! (Entrevistado número 3).
\end{abstract}

Com base nesse panorama, compreendeu-se que no caso específico da commodity soja, ora referendada enquanto valor de troca, sua dinâmica (produtividade e lucratividade) se disseminou na preeminente competitividade alcançada no mercado internacional ao longo dos anos, atingindo vantajoso nível de preços, posto que a padronização produtiva era orientada pelas tradings (multinacionais) do setor agropecuário. Esse pressuposto se adequou aos esclarecimentos de Elias (2006a), de que em função do advento da agricultura em larga escala 
se intensificam as determinações externas ao lugar de produção, especialmente por mercados cada vez mais distantes e competitivos, e controlados pelas principais bolsas de valores do mundo.

Por outro lado, observou-se que a ocupação empresarial em Uruçuí acentuou a problemática da concentração fundiária, já que 100\% dos empreendimentos investigados incorporavam o grupo de área superior a 3.000 hectares. Essa situação revelava que a instalação da agricultura empresarial além de repercutir na redução do acesso à terra aos agricultores familiares, os restringia do domínio das áreas de uso coletivo.

Tal contexto se coadunou com as análises de Monteiro e Aguiar (2006, p.221), de que a aquisição de terra em Uruçuí, a preços ditos “simbólicos”, representou, historicamente, relevante forma de acumular riquezas, com destaque para a constituição do mercado de terras, haja vista que o processo avançou de acordo com os interesses de empresários agropecuários e investidores econômicos. Por isso, asseguram que:

[...] o descontrole no padrão de ocupação e uso da terra no município leva a acreditar não haver nenhuma preocupação por parte dos governantes em relação aos impactos das novas atividades econômicas sobre o solo, os recursos hídricos e o uso de tecnologias inapropriadas ao contexto socioambiental. Ou seja, não obstante existir um arcabouço institucional com condições de regulamentar o processo de apropriação da terra, este é frágil e, assim, não possui capacidade de promover uma ocupação racional, até porque sua regulação é regida pelos interesses dos agentes econômicos com melhores condições para adquirir vastas extensões de terras. Logo, o processo de ocupação das terras de Uruçuí, até a década de 1980, caracteriza-se pelo desbravamento, no sentido de que o desmatamento da terra implica a garantia da posse e sua valorização, revelando o caráter eminentemente patrimonialista.

Acerca do preço da terra em Uruçuí, inferiu-se, consoante $100 \%$ dos graníferos, que a valorização se encontrava determinada por fatores, como: ser a terra limpa e produtiva, estar bruta (florestada) e/ou infraestrutura existente. Aliás, nesse particular, prevalecia a negociação por meio do valor da saca de soja $(60 \mathrm{~kg})$ no mercado, como explicou um granífero.

A terra produzindo custa em torno de 200 sacas de soja por hectare, mas área absolutamente corrigida, considerando o teor de alumínio zero, saturação de base em torno de $60 \%$; fósforo, cálcio, potássio, esses teores envolvidos. Agora, aí é aquela história, se você tem 10 mil hectares, você não está com 10.000 ha abertos, você tá com 5 mil ha, porque tu tem a reserva. Tu teria que fazer uma média, como: área aberta vale 200 sacas, área semiaberta outro valor, e assim por diante (Entrevistado número 2). 
Registra-se que essa constatação se coadunou com o ponto de vista de Kautsky (1986), de que o valor de um hectare de terra é definido com base no cálculo da renda fundiária e dos meios de produção criados pelo trabalho humano (construções, instalações e invenções técnicas).

Salienta-se, consoante com Kautsky (1986, p.71), que a renda fundiária consiste em um lucro extra ou extraordinário proveniente dos diferentes graus de fertilidade do solo e da posição geográfica favorável da propriedade em relação ao mercado consumidor. Sendo assim, pontua que o agricultor que explora a terra, mas não é dono da mesma, "tem que pagar por essa permissão entregando parte de seu lucro extraordinário, da sua renda fundiária”.

Acrescenta-se, segundo Alves (2006, p.240), que em meados da década 1980, "as terras planas dos platôs valiam bem menos, costumava-se dizer, na região, que o hectare poderia ser adquirido pelo preço de uma cerveja”. E que no final da década, o mesmo hectare custava apenas uma saca de soja. Mas, nos anos 1990, pagava-se por este hectare dez sacas de soja. Já em 2005, um hectare de terra bruta nos planaltos de Uruçuí era vendido pelo preço médio de 30 sacas de soja, e a saca era negociada, em média, a $\mathrm{R} \$ 24,00$.

A propósito, Lima Filho (2016) reclama o agravamento daquele cenário quando analisa as transações de compra e venda de terras em Uruçuí, onde, em dezembro de 2015, o preço médio computava $\mathrm{R} \$ 5.500,00 /$ ha, com valores máximos de $\mathrm{R} \$ 8.000,00 /$ ha; ou seja, a terra em Uruçuí se transformou em um ativo de alta liquidez, uma vez que o preço médio era menor quando comparado aos de outras regiões de elevada produção agrícola, como Rio Formoso (TO), Balsas (MA) e o extremo oeste baiano, lugares onde o preço médio da terra era negociado por $\mathrm{R} \$ 7.300,00 /$ ha, $\mathrm{R} \$ 8.400,00 /$ ha e $\mathrm{R} \$ 9.100,00 /$ ha, respectivamente.

Deste modo, concorda-se com Monteiro e Aguiar (2006), quando reiteram que a terra em Uruçuí se transformou em um produto de significativa lucratividade, na medida em que o valor em si era subordinado às condições prevalecentes, como características naturais, intervenções técnicas e nível de produtividade, bem como ao comportamento do mercado, pois à medida que crescia a demanda por terra, os preços se elevavam.

\section{O USO INTENSIVO DE CAPITAL, TECNOLOGIA E INFORMAÇÃO}


Não obstante o pioneirismo dos graníferos no cerrado piauiense, destaca-se a infraestrutura disponibilizada, principalmente por meio de medidas governamentais, implementadas a partir dos anos 1990, para dar sustentação às funções da nova base técnica.

Dentre tais medidas, Monteiro e Aguiar (2006) e Peixinho e Scopel (2009) reconhecem o FINOR-Agropecuário e o Fundo Constitucional de Financiamento do Nordeste (FNE), o Programa Nordeste Competitivo, lançado em 1993, cuja responsabilidade era do BNDES, a Lei $\mathrm{n}^{\mathrm{o}}$ 4.859, de 27 de agosto de 1996, que concedia isenção fiscal sob o ICMS, entre 60 a 100\%, em até 15 anos, conforme o tipo de empresa que desejasse se instalar, e o Polo de Desenvolvimento Integrado Uruçuí/Gurgueia, criado em 1998, para a construção de uma política de desenvolvimento territorial nos cerrados do sul do Piauí.

Tais ações institucionais promoveram a modernização produtiva e a instalação de indústrias e agroindústrias, como a Bunge Alimentos, por exemplo (ALVES, 2012). Por outro lado, induziram à expansão da fronteira agrícola, via valorização especulativa de terras, o que contribuiu para a concentração fundiária, como também para a substituição da cultura extensiva por intensiva (ALVES, 2009).

De fato, inferiu-se, por meio do trabalho empírico, que a disponibilidade de infraestruturas representava um mecanismo subvencionador para atração de empresas de agronegócios para Uruçuí, na medida em que potencializava a escala da produção, o que confirmou a crítica de Bernardes (2015), de que a criação de infraestruturas materializa os custos envolvidos na implantação das condições gerais da acumulação capitalista na fronteira.

Ressalta-se, em consonância com Peixinho e Scopel (2009), que a Bunge Alimentos S.A. instalou-se no município em 2002, e passou a ser além de principal fornecedora de farelo e óleo para o Piauí, Ceará e Pernambuco, compradora de grãos, sobretudo, soja in natura, de outros estados, principalmente Maranhão e Tocantins.

Em conformidade com Alves (2012, p.241), atesta-se que a presença da multinacional no cerrado piauiense modificou substancialmente as relações de comercialização e circulação de produtos oriundos da agropecuária local, uma vez que instituiu formas de monopolização na compra de soja, na venda de fertilizantes para os produtores e no financiamento das safras. Relata que esses fatores foram responsáveis pelo incremento da produção de commodities e pela subordinação dos graníferos aos interesses da empresa. Sublinha ainda que a instalação da agroindústria em Uruçuí "significou também o aumento de problemas ambientais e o desaparecimento dos meios de reprodução da vida das populações locais". 
Essa estratégia empresarial ao espelhar um tipo específico de parceria, no qual o principal elo de dependência entre os graníferos e a referida agroindústria se dava pelo empréstimo de capital que essa fazia aos primeiros, expressou a concepção de Elias (2006b), de que nos cerrados, as agroindústrias antecipam o capital da compra da produção na época do plantio, substituindo os créditos bancários no fornecimento de capital de custeio. Dessa forma, praticamente tornam os graníferos seus fornecedores exclusivos, e asseguram a matéria-prima para a produção.

Tal atuação agroindustrial também confirmou a crítica de Souza (2009, p.157), de que:

Sob a ótica das cadeias agroindustriais, quanto maior a utilização e aquisição de fertilizantes, inseticidas, sementes e máquinas, maior será o grau de dependência técnico/produtiva e econômica do trabalhador. Assim, também maior o grau de transferência do resultado de seu trabalho aos outros setores do capitalismo mercantil e industrial, seja na forma monetária ou em produtos.

Outrossim, o protagonismo governamental para a consolidação do agronegócio em Uruçuí, refletiu as proposições de Araújo e Araújo (2007, p.41), de que as intervenções do Estado permitiram identificá-lo como mediador e conciliador dos interesses dominantes, o que assegurou "a criação de políticas públicas e de infraestruturas necessárias ao desenvolvimento desse processo e, de um modo geral, desconsiderando as questões socioeconômicas, culturais e ambientais decorrentes".

Com base nos referidos autores, conferiu-se que $100 \%$ dos graníferos atribuíam às políticas do Estado inexorável atuação no processo de ocupação do cerrado, as quais se materializavam, por exemplo, por meio da formação de um importante sistema de circulação intermodal, que incluiu a ampliação da rodovia BR-135 e a construção da PI-397 (Rodovia Transcerrados), as quais criaram as condições para maior fluidez das mercadorias produzidas em Uruçuí.

Verificou-se que a modernização na agricultura uruçuiense, representou um processo através do qual os graníferos procuraram dominar determinadas formas e/ou etapas da produção, visando garantir à progressividade das safras e, consequentemente, o aumento dos lucros, o que repercutia diretamente no controle sobre o espaço geográfico. Esse fato se coadunou com a concepção de Lênin (1982), de que as diversas modificações incrementadas na técnica agrícola são indissociáveis umas das outras e acarretam inevitáveis transformações do sistema econômico. 
Todavia, Peixinho e Scopel (2009) compreendem que a conformação dessa nova paisagem (artificializada) desperta, no imaginário social, o sinônimo de agricultura moderna, pujante, em contraposição às áreas cultivadas por agricultores familiares de culturas tradicionais.

Portanto, ressalta-se que a potencialidade e efetividade do agronegócio em Uruçuí fundamentaram-se na relação terra/infraestrutura/geoambiente/mercado, o que exigiu novos significados para o trabalho agrícola e novas práticas socioprodutivas. Nessa perspectiva, Monteiro e Aguiar (2006, p.224) enfatizam que:

\footnotetext{
[...] entre os motivos que condicionam os empresários agropecuários a recorrerem ao município para instalar seus negócios, além do baixo preço da terra, mencionam-se a vocação e qualidade da terra para a produção de grãos. Ademais, a chapada plana facilita a mecanização e as condições de localização são bastante favoráveis em relação ao destino das exportações dos grãos, diante da proximidade do porto de Itaqui (MA) e em relação às vantagens oferecidas pela proximidade da demanda do mercado interno - a região Nordeste como um todo.
}

Acentua-se que esse cenário, disseminou em Uruçuí uma agricultura moderna, homogeneizada, seletiva, e ao mesmo tempo, conectada às decisões do mercado global, pois $100 \%$ dos graníferos se utilizavam dos dados disponíveis de bolsas de valores para programar e comercializar os grãos. Essa particularidade se harmoniza com a preposição de Bruno (2009, p.115), de que o agronegócio exprime a imagem de um setor competitivo e integrado aos padrões de consumo no mundo, já que se estrutura por meio "da noção de cadeia e de elos que uniriam processos, empresas e atores. Ou seja, segundo seus porta-vozes, o modo de configuração do processo produtivo, sistêmico, constrói a união".

Nesse sentido, verificou-se que a incorporação do cerrado local ao agronegócio conferiu um outro sentido à agropecuária, substituindo seu valor de uso pelo valor de troca, personificado nas chamadas práticas espaciais de seletividade e fragmentação. Essa contextura se coadunou à percepção de Aracri (2009), que concebe as práticas espaciais como formas através das quais as firmas e os agentes econômicos fazem a apropriação e dominação dos recursos (que inclui as pessoas e a natureza), posto que as áreas selecionadas sejam propositadamente utilizadas como instrumento de manipulação política e ideológica.

A pesquisa de campo apontou que o uso intensivo de inovações tecnológicas, como mecanização, insumos químicos e sementes melhoradas, era largamente disseminado entre os graníferos, haja vista que $100 \%$ justificaram o manejo em razão de ganhos em produtividade.

Outrossim, detectou-se que a mecanização, cujo único objetivo era substituir a força de trabalho humana ou animal, era empregada em todas as etapas da produção agrícola e, por esse 
motivo, destacou-se como uma das inovações mais generalizadas e massificadas nos empreendimentos graníferos, sendo representada por uma ampla variedade de máquinas, como tratores, plantadeiras, pulverizadores, colheitadeiras, distribuidores de calcários, avião agrícola e outros implementos diversos.

\section{PRODUÇÃO, MERCADO E NOVOS PERFIS DE MÃO DE OBRA NO TRABALHO AGRÍCOLA DE URUÇUÍ}

Sem embargo, descobriu-se que na totalidade dos empreendimentos investigados, se por um lado, o emprego sistemático de maquinário elevava a produtividade do trabalho agrícola, por outro lado, diminuía a demanda por mão de obra assalariada, devido à máquina substituíla. Essa assertiva se harmonizou com a concepção de Lênin (1982, p.148), na qual "a introdução de máquinas implica ponderáveis capitais, o que a torna acessível apenas aos grandes proprietários", além do mais, "o investimento com as máquinas só se amortiza sob um imenso volume do produto manufaturado. Com as máquinas, a ampliação da produção se torna uma necessidade".

Da mesma maneira, conferiu-se por meio da pesquisa empírica, a magnitude do consumo de insumos químicos, entre os graníferos $(100 \%)$, o que provocou a dependência para o incremento de corretivos, defensivos, fertilizantes e sementes geneticamente melhoradas. Segundo Aracri (2009), essas inovações constituem uma extensa variedade de produtos disponíveis, que apresentam variações de acordo com os distintos tipos de cultura, clima e solo.

Como também, explicitou que $100 \%$ dos graníferos incluíam, no planejamento das safras, serviços especializados de consultoria privada, voltados para análises de solo, de modo a definir o volume e os tipos de matérias-primas utilizados nas lavouras, e dessa forma, assegurarem melhores rendimentos. Essa situação refletiu a argumentação de Bernardes (2009), no sentido de que as técnicas contribuem para superar grande parte das dificuldades do cerrado, fazendo com que os níveis de produção se intensifiquem a cada nova lavoura.

Observou-se ainda, que a tomada de decisão sobre os tipos sementes, os distintos insumos químicos empregados e a quantidade de área a ser ocupada e maquinário, era fundamentada nas perspectivas e nas condições do mercado, já que $100 \%$ dos graníferos reconheciam a influência das tradings nas operações de produção, circulação e consumo. Essa configuração se relacionou à compreensão de Elias (2006b) de que a continuidade da agricultura em larga escala no cerrado está condicionada à dinâmica do mercado, particularmente o global, posto determinar o nível dos preços e como as tradings controlam o 
financiamento e a comercialização, o calendário agrícola é ordenado em função dos interesses do mercado.

De fato, percebeu-se que a prática de cultivar soja transgênica sob o sistema de plantio direto com base nos sintéticos, representava a possibilidade de elevação dos índices de produtividade, uma vez que $100 \%$ dos graníferos classificavam as sementes transgênicas como resistentes a secas e solos ácidos e contra ataques de pragas, vírus, insetos e fungos. Contudo, entendeu-se, alicerçado em Porto-Gonçalves (2011, p.240), que esse modelo agrícola era ambíguo, pois, por um lado, proporcionava a redução dos custos de produção, "principalmente de mão de obra, na medida em que os produtores já não têm que realizar tarefas de combate a pragas, além disso, as técnicas de plantio direto facilitam, também, as tarefas de semeadura" e, por outro lado, acentuava a dependência dos produtores diante do complexo industrial/financeiro e, com isso, agravava a tendência de diminuição dos postos de trabalho, "instalando uma agricultura sem agricultores".

Diante disso, encerra-se, segundo a Tabela 1, que o agronegócio se manifestava em Uruçuí, priorizando as mercadorias mais valorizadas nas bolsas de valores.

Consoante a Tabela 1, verificou-se que as principais lavouras cultivadas por $100 \%$ dos graníferos eram: soja, milho, milheto, arroz e sorgo, representando 41,4\%, 37,9\%, 11,0\%, 6,2\% e $3,5 \%$ respectivamente, do total de área plantada na safra $2014 / 2015$, fixada em 14.500 hectares. A respeito da quantidade colhida, estimada em 57.150 toneladas, predominou o milho, com $64,0 \%$, seguido por soja $(27,3 \%)$, sorgo $(3,7 \%)$, milheto $(3,1 \%)$ e arroz $(1,9 \%)$.

Tabela 1 - Produção agrícola em Uruçuí, safra 2014/2015, segundo os produtores rurais

\begin{tabular}{l|c|c|c|c}
\hline \multirow{2}{*}{ Produto } & \multirow{2}{*}{$\begin{array}{c}\text { Área plantada } \\
\text { (ha) }\end{array}$} & $\begin{array}{c}\text { Colheita } \\
(\mathrm{t})\end{array}$ & $\begin{array}{c}\text { Comerciado Interno } \\
(\mathrm{t})\end{array}$ & $\begin{array}{c}\text { Mercado Externo } \\
(\mathrm{t})\end{array}$ \\
\hline Milho & 5.500 & 36.550 & 13.870 & 22.680 \\
Soja & 6.000 & 15.600 & 5.502 & 10.098 \\
Sorgo & 500 & 2.100 & 2.100 & - \\
Milheto & 1.600 & 1.800 & 1.800 & - \\
Arroz & 900 & 1.100 & 1.100 & - \\
\hline Total & 14.500 & 57.150 & 24.372 & 32.778 \\
\hline
\end{tabular}

Fonte: Pesquisa direta, janeiro/julho de 2015

Tal desempenho contribuiu para a dinâmica do mercado internacional, já que 57,3\% da produção (32.778 toneladas) destinaram-se às exportações, enquanto 42,7\% (24.372 toneladas) permaneceram no país. À vista disso, constatou-se que milho e soja eram os plantios mais 
valorizados pelos graníferos, representando $100 \%$ das vendas externas $(69,2 \%$ eram milho e $30,8 \%$ soja) e $79,5 \%$ das vendas internas ( $56,9 \%$ eram milho e $22,6 \%$ soja). E que as culturas de sorgo, milheto e arroz se destacavam no mercado doméstico, principalmente o nordestino, uma vez que corresponderam, respectivamente $8,6 \%, 7,4 \%$ e $4,5 \%$ do total negociado na região.

Assim, inferiu-se que os graníferos privilegiavam o plantio de mercadorias com maior taxa de lucratividade, conforme o raciocínio capitalista, posto que as commodities milho e soja se sobressaiam sob os cultivos de sorgo, milheto e arroz, apresentando, dessa forma, competitividade nos mercados global e regional.

Todavia, entendeu-se que tal particularidade demonstrava uma situação controversa, pois ao direcionarem o modelo produtivo ao paradigma econômico dominante, ficaram expostos às incertezas das leis de mercado, variando as margens de lucro. Desse modo, reafirmou-se que a espacialização da agricultura empresarial em Uruçuí era subordinada pelo mercado, desencadeando novos sentidos à produção agrícola.

Não obstante a importância dos mercados para a continuidade do agronegócio em Uruçuí, assinala-se que não foi possível examinar, com precisão, o processo de escoamento da produção, particularmente, para o exterior. Por essa razão, reconheceu-se a necessidade de estudos futuros para subsidiar a elucidação do problema. Para tanto, se sugerem questões norteadoras, como: quais as políticas públicas específicas para as exportações de produtos agrícolas de Uruçuí e as consequências para o desenvolvimento local? Como se organiza a engenharia dos sistemas de transporte, armazenamento e processamento para a produção pósvenda? Quais as principais rotas internacionais das mercadorias uruçuienses? Qual o perfil social, econômico, cultural e ambiental dos países consumidores? Esse perfil interfere na lógica produtiva das fazendas de Uruçuí?

Compreendeu-se que a difusão de capital, tecnologia e informação nos empreendimentos graníferos intensificou a hierarquização de tarefas, produtivas e/ou administrativas, o que redundou na diminuição de mão de obra por área cultivada, ratificando a opinião de Kautsky (1986), de que a grande propriedade poupa energia humana, pois devido ao uso de tecnologia, e da intelectualização do trabalho manual, aproveita melhor as áreas de cultivo. Com vistas a ilustrar essa constatação, detalha-se, na Tabela 2, a relação entre a área cultivada e a quantidade de trabalhadores empregados nos empreendimentos, na safra $2014 / 2015$ 
Tabela 2 - Quantidade de trabalhadores, por área cultivada, na safra 2014/2015, na agricultura empresarial de Uruçuí

\begin{tabular}{c|c|c|c}
\hline $\begin{array}{c}\text { Empreendimento } \\
\text { granífero }\end{array}$ & Área cultivada (ha) & $\begin{array}{c}\text { Número de } \\
\text { trabalhadores }\end{array}$ & Hectares/Trabalhador \\
\hline A & 9.700 & 31 & 440,1 \\
B & 3.000 & 21 & 176,5 \\
C & 1.800 & 15 & 120,0 \\
\hline Total & 14.500 & 67 & 216,4 \\
\hline
\end{tabular}

Fonte: Pesquisa direta, janeiro/julho de 2015

Por meio da Tabela 2, observou-se a predominância da modernização agrícola, uma vez que na safra 2014/2015, a relação entre a área cultivada e o número de trabalhadores necessários para a produção foi de 216,4 hectares por trabalhador. Salienta-se que esse contexto foi distinto da realidade encontrada por Arruzzo (2009), que em 2007, identificou 74 hectares por trabalhador na colheita de soja no sudoeste piauiense, justificando a premissa de que o agronegócio granífero se perpetuava estruturado na tríade mecânica/química/biológica.

Conferiu-se que quanto ao grau de instrução e a quantidade de trabalhadores empregados nos empreendimentos, em Uruçuí o agronegócio se manifestava de maneira contraditória, pois à medida que intensificava o incremento do aparato tecnológico, diminuía a demanda por postos de trabalho, gerando novos perfis de mão de obra. Essa opinião vai ao encontro das argumentações de Ribeiro, Mendonça e Hespanhol (2002), de que o desenvolvimento do capital na agricultura promove especializações regionais e muitas vezes provoca geografizações diversas (contrastes socioespaciais), cujos reflexos mais contundentes são as alterações das relações de trabalho.

\section{CONSIDERAÇÕES FINAIS}

Respondendo às questões levantadas para esta investigação, constatou-se que embora as condições ambientais do cerrado piauiense favorecessem a ocupação capitalista, intensificada a partir dos anos 1990, a configuração de um novo patamar produtivo conformouse, sobretudo, em fatores de ordem política e econômica, como o baixo preço da terra, redes técnicas e a dinâmica dos mercados doméstico e global.

Os empresários e investidores econômicos que desembarcaram em Uruçuí tinham, em maioria, laços culturais com a agricultura familiar. Ademais, o processo migratório contou e continua contando com a participação substancial do Estado e das políticas públicas, por meio de incentivos fiscais, terras, infraestruturas, créditos, investimentos em pesquisas, etc., 
contribuindo, portanto, para a reprodução ampliada do capital via expansão do território, o que repercutiu na concentração fundiária e constituição de um lucrativo mercado imobiliário de terras. Essa situação personifica a concepção de que o Estado está a serviço dos agentes do capital.

Compreendeu-se também que a soja representava a cultura mais valorizada nos plantios de Uruçuí, sendo estrategicamente empregada nas negociações de terras e nas aquisições de capital de custeio, o que tornava os graníferos os fornecedores exclusivos da matéria-prima para as agroindústrias.

A partir do exposto pode-se inferir que o processo de ocupação empresarial do cerrado piauiense, como em Uruçuí, não se esgotou. O modelo expansionista modernizador, por um lado, elevou a produtividade da terra e do trabalho, conferindo uma formidável competitividade das mercadorias nos mercados doméstico e global. Por outro lado, ampliou as diferenças sociais, na medida em que conservou velhas questões territoriais, como concentração da riqueza, manutenção do latifúndio, hierarquização social, seletividade espacial e subordinação do agricultor familiar.

Além desses aspectos, a expansão da agricultura empresarial elevou os problemas ambientais, como os desmatamentos e o uso de sintéticos, por exemplo. Assim, não custa compreender que o modelo de desenvolvimento imposto para o avanço da fronteira agrícola em Uruçuí apresenta-se contraditório.

\section{REFERÊNCIAS}

AGUIAR, T. J. A; MONTEIRO, M. S. L. Modelo agrícola e desenvolvimento sustentável: a ocupação do cerrado piauiense. Ambiente \& Sociedade, Campinas, v. 8, n. 2, pp. 1-18, 2005.

ALVES, V. E. L. As bases históricas da formação territorial piauiense. Geosul, Florianópolis, v. 18, n. 36 , pp. 55-76, 2003.

Mobilidade do trabalho e reprodução do capital nos cerrados piauienses. Boletim

Goiano de Geografia, Goiânia, v. 24, n. 1-2, pp. 43-53, 2004.

Os cerrados piauienses e sua nova lógica de reprodução capitalista. In: ELIAS, D.;

PEQUENO, R. (Orgs.). Difusão do agronegócio e novas dinâmicas socioespaciais.

Fortaleza: Banco do Nordeste do Brasil, 2006, pp. 235-258.

O mercado de terras nos cerrados piauienses: modernização e exclusão. Agrária, São Paulo, n. 10-11, pp. 73-98, 2009. 
. A presença da grande empresa do agronegócio nos cerrados nordestinos: o caso da Bunge Alimentos no sul do Piauí. Boletim Campineiro de Geografia, Campinas, v. 2, n. 2, pp. 241-261, 2012.

ARACRI, L. A. S. A difusão da base técnica da sojicultura no cerrado baiano. In: BERNARDES, J. A.; BRANDÃO FILHO, J. B. (Orgs.). A territorialidade do capital: geografias da soja II. Rio de Janeiro: Arquimedes Edições, 2009, pp. 42-54.

ARAÚJO, M. R. S.; ARAÚJO, J. L. L. A instituição dos cerrados piauienses como fronteira agrícola: o estado e os capitais privados reorganizando espaços. In: LOPES, W. G. R. [et al.]. Cerrado piauiense: uma visão multidisciplinar. Teresina: Edufpi, 2007, pp. 31-52.

ARRUZZO, R. C. O moderno e o arcaico no trabalho na agricultura moderna nos cerrados do Norte e Nordeste do Brasil. In: BERNARDES, J. A.; BRANDÃO FILHO, J. B. (Orgs.). A territorialidade do capital: geografias da soja II. Rio de Janeiro: Arquimedes Edições, 2009, p. 56-68.

BERNARDES, J. A. Fronteiras da agricultura moderna no cerrado Norte/Nordeste: descontinuidades e permanências. In: BERNARDES, J. A.; BRANDÃO FILHO, J. B. (Orgs.). A territorialidade do capital: geografias da soja II. Rio de Janeiro: Arquimedes Edições, 2009, pp.13-39.

Novas fronteiras do capital no cerrado: dinâmica e contradições da expansão do agronegócio na região Centro-Oeste, Brasil. Scripta Nova (Revista Electrónica de Geografía y Ciencias Sociales), Barcelona, v. XIX, p. 507, 2015.

BRUNO, R. Tempo do agronegócio no Brasil: agronegócio, palavra política. In: BRUNO, R.; CARVALHO, A. V.; BORDADO, C. A.; SEVÁ, J. T.; VIEIRA, M. A. C.; CARNEIRO, O. B.; AQUINO, S. L. Um Brasil ambivalente: agronegócio, ruralismo e relações de poder. Rio de Janeiro: Mauad X; Seropédica, RJ: Edur, 2009, pp. 113-129.

ELIAS, D. Globalização e fragmentação do espaço agrícola no Brasil. Scripta Nova (Revista Electrónica de Geografía y Ciencias Sociales), Barcelona, v. X, n. 218, p. 3, $2006 a$.

. Agronegócio e desigualdades socioespaciais. In: ELIAS, D.; PEQUENO, R. (Orgs.). Difusão do agronegócio e novas dinâmicas socioespaciais. Fortaleza: Banco do Nordeste do Brasil, 2006b, pp. 25-82.

. Les territoires de 1'agrobusiness au Brésil. Confins, Paris, v. 15, pp. 1-20, 2012.

FAÇANHA, A. C.; LEAL, M. N. Transformações no urbano do Piauí: o caso de Bom Jesus. In: BERNARDES, J. A.; BRANDÃO FILHO, J. B. (Orgs.). A territorialidade do capital: geografias da soja II. Rio de Janeiro: Arquimedes Edições, 2009, pp.137-149.

HAESBAERT, R. "Gaúchos" e "Baianos" no "Novo" Nordeste: entre a globalização econômica e a reinvenção das identidades territoriais. In: CASTRO, I. E.; GOMES, P. C. C.; CORRÊA, R. L. (Orgs.). Brasil: questões atuais da reorganização do território. 3. ed. Rio de Janeiro: Bertrand Brasil, 2005, pp. 367-415. 
IBGE. Instituto Brasileiro de Geografia e Estatística. Sidra: produção agrícola municipal. (2017). Disponível em: https://sidra.ibge.gov.br/tabela/1612. Acesso em 22 de novembro de 2018.

KAUTSKY, K. A questão agrária. São Paulo: Nova Cultural, 1986.

LÊNIN, V. I. O desenvolvimento do capitalismo na Rússia: o processo de formação do mercado interno para a grande indústria. São Paulo: Abril Cultural, 1982.

LIMA FILHO, R. R. Terras: esfriaram os negócios no País. Agroanalysis, São Paulo, pp. 2628, jan., 2016.

MANZINI, E. J. Considerações sobre a entrevista para a pesquisa social em educação especial: um estudo sobre análise de dados. In: JESUS, D. M.; BAPTISTA, C. R.; VICTOR, S. L. Pesquisa e educação especial: mapeando produções. Vitória: UFES, 2006, p. 361-386.

MARTINS, J. S. Fronteira: a degradação do Outro nos confins do humano. 2. ed. São Paulo: Contexto, 2014.

MONTEIRO, M. S. L.; AGUIAR, T. J. A. Ocupação do cerrado piauiense: valorização fundiária e consequências ambientais. In: ELIAS, D. S.; PEQUENO, R. (Orgs.). Difusão do agronegócio e novas dinâmicas socioespaciais. Fortaleza: Banco do Nordeste do Brasil, 2006, pp. 211-233.

OLIVEIRA, M. M. Como fazer pesquisa qualitativa. 7. ed. Petrópolis: Vozes, 2016.

ORLANDI, E. P. Análise do discurso: princípios e procedimentos. Campinas: Pontes, 2000.

PACHECO, J. C. Impactos ambientais na produção de ração para frango de corte em uma cooperativa de avicultores piauiense. 2017. 130 fls. Tese (Doutorado em Desenvolvimento e Meio Ambiente), Programa de Pós-Graduação em Desenvolvimento e Meio Ambiente, Universidade Federal do Piauí, Teresina.

PEIXINHO, D. M.; SCOPEL, I. A territorialização da agricultura moderna no Piauí. In: BERNARDES, J. A.; BRANDÃO FILHO, J. B. (Orgs.). A territorialidade do capital: geografias da soja II. Rio de Janeiro: Arquimedes Edições, 2009, pp. 89-113.

PORTO-GONÇALVES, C. W. A globalização da natureza e a natureza da globalização. 2. ed. Rio de Janeiro: Civilização Brasileira, 2011.

QUEIROZ, M. I. P. Variações sobre a técnica do gravador no registro da informação viva. 2. ed. São Paulo: CERVE/FFLCH/USP, 1983.

RIBEIRO, D. D.; MENDOÇA, M. R.; HESPANHOL, A. N. Relações de trabalho na agricultura mecanizada: a monocultura da soja em Goiás. Scripta Nova (Revista Electrónica de Geografía y Ciencias Sociales), Barcelona, v. VI, n. 119, p. 81, 2002. 
SANTOS, I. E. Manual de métodos e técnicas de pesquisa cientifica. 9. ed. Niterói: Impetus, 2012.

SANTOS, R. W. P.; ARAÚJO, J. L. L. Os cerrados piauienses na geopolítica da soja. In: LOPES, W. G. R. [et al.]. Cerrado piauiense: uma visão multidisciplinar. Teresina: Edufpi, 2007, pp. 79-96.

SAQUET, M. A. Abordagens e concepções de território. 4. ed. São Paulo: Outras Edições, 2015.

\section{SILVA, A. J. Agricultura familiar e a} territorialização/desterritorialização/reterritorialização provocada pelo agronegócio no cerrado piauiense: hibridismo sociocultural marginal em Uruçuí. 325 fls. Tese (Doutorado em Desenvolvimento e Meio Ambiente), Trópico Ecotonal do Nordeste, Universidade Federal do Piauí, Teresina, 2016.

SILVA, A. J.; MONTEIRO, M. S. L.; BARBOSA, E. L. Nova dinâmica produtiva e velhas questões territoriais nos cerrados setentrionais do Brasil. Revista Espacios, Caracas, v. 36, n. 21, p. 14, 2015.

. Territorialização da agricultura empresarial em Uruçuí/PI: de "espaço vazio" aos imperativos do agronegócio. Caderno de Geografia, Uberlândia, v. 27, n. esp. 1, pp. 138$158,2017$.

SOUZA, J. G. A geografia agrária e seus elementos de crítica sobre os avanços do capital monopolista no campo brasileiro. Canadian Journal of Latin American and Caribbean Studies, Montréal, v. 34, n. 68, pp. 147-175, 2009.

VELHO, O. G. Frentes de expansão e estrutura agrária: estudo do processo de penetração numa área da Transamazônica. Rio de Janeiro: Zahar Editores, 1972.

Recebido em Maio de 2019

Aprovado em Agosto de 2019

Publicado em Agosto de 2019 